\title{
RANCANGAN JIG DAN FIXTURE PEMBUATAN PRODUK COVER ON-OFF
}

\author{
Hendro Prassetiyo ${ }^{1}$, Rispianda $^{2}$, Haris Adanda ${ }^{3}$ \\ Jurusan Teknik Industri, Institut Teknologi Nasional ${ }^{1,2,3)}$, \\ Bandung, Jawa Barat \\ E-Mail : prasshendro@gmail.com ${ }^{1}$,rispianda@gmail.com ${ }^{2}$
}

\begin{abstract}
The manufacturing industry has been growing rapidly at this time, it can be seen from the number of manufacturing companies that have emerged and growing. Obstacles often occur over production activity in a manufacturing company is a long setup times and product quality in production activities which will indirectly affect the output product to be produced. The longer of the setup activities will result in the output of products which are getting smaller. Improved product quality and minimize setup time can be done either by the use of tools manufacturing which is often known as jigs and fixtures. This paper will discuss the design of jig and fixture for manufacture products cover on-off. Jigs and fixtures are designed to be used for the process drilling for three holes. Jig and Fixture design results can provide a reduction in total time of manufacture of the product, product quality improvements, increased productivity and cost saving product manufacture for products cover on-off.
\end{abstract}

Keywords: Jig, Fixture, Quality, Setup Time, Manufacture.

\section{PENDAHULUAN}

Perusahaan manufaktur sejatinya memiliki peranan penting di dalam dunia industri untuk memproduksi suatu produk. Seiring dengan berkembangnya jaman, perusahaan-perusahaan industri yang bergerak dalam dunia manufaktur semakin bertambah. PT. X merupakan salah satu industry manufaktur yang salah satunya varian produk yang diproduksinya adalah komponen cover on-off. Cover on-off berfungsi sebagai salah satu komponen dari sistem pengereman kereta api dimana pada kegiatan produksi dalam pembuatan cover on-off ini telah memanfaatkan penggunaan alat bantu jig dan fixture. Jig dan fixture pada dasarnya merupakan suatu alat bantu yang digunakan dalam proses pemesinan agar dapat menghasilkan duplikasi part yang lebih akurat. Fixture merupakan suatu alat bantu yang berfungsi untuk memposisikan, memegang, dan menahan benda kerja selama proses produksi atau proses permesinan. Sedangkan jig pada alat bantu jig dan fixture berfungsi sebagai alat utama yang berperan untuk mengarahkan mata pahat pada benda kerja yang akan di proses sesuai operasi yang di inginkan.
Penggunaan alat bantu jig dan fixture pada pembuatan salah satu komponen pengereman kereta api cover on-off ini terdiri dari tiga buah alat bantu yang memiliki fungsi proses yang berbeda pada permukaan benda kerja cover on-off, sehinggga dibutuhkan kegiatan setup yang cukup besar untuk memproses satu buah komponen cover on-off. Alat bantu yang di pergunakan sampai dengan saat ini belum menjamin ketepatan dalam pemasangan (folproof), sehingga dapat terjadi kesalahan dalam pemasangan benda kerja cover on-off tersebut. Kesalahan pemasangan alat bantu dapat mengakibatkan produk cover on-off mengalami cacat karena posisi lubang yang tidak simetris. Permasalahan tersebut dapat mengakibatkan posisi lubang yang tidak simetris pada produk cover on-off, serta memiliki waktu setup yang cukup lama. Waktu setup yang dihasilkan oleh penggunaan ketiga buah alat bantu ini pun cukup lama karena membutuhkan waktu setup tersendiri untu masing - masing proses yang dilakukan pada produk cover on-off. Oleh karena itu dibutuhkan penyederhanaan dan perancangan ulang alat bantu produksi agar waktu setup dan kesalahan pada saat 
pemasangan komponen pada alat bantu dapat diminimumkan. Makalah ini akan membahas perancangan alat bantu jig and fixture untuk memproduksi komponen cover on-off, sehingga dapat mengurangi waktu setup, meningkatkan produktivitas dan memudahkan penggunaan.

\section{METODOLOGI PENELITIAN}

Jig dan fixture merupakan alat bantu produksi yang digunakan pada proses manufaktur sehingga dihasilkan duplikasi part yang akurat. Hubungan yang tepat dan sejajar antara pemotong, atau alat yang lain, dan benda kerja harus dijaga. Jig dan fixture merupakan alat bantu produksi yang digunakan pada proses manufaktur, sehingga dihasilkan duplikasi part yang akurat. Jig dan fixture biasanya dibuat secara khusus sebagai alat bantu proses produksi untuk mempermudah dalam penyetingan material yang menjamin keseragaman bentuk dan ukuran produk dalam jumlah banyak serta untuk mempersingkat waktu produksi. Jig adalah peralatan khusus yang berfungsi untuk memegang, menahan dan menyokong benda kerja yang akan mengalami proses pemesinan. Jig tidak hanya menahan dan menyokong benda kerja, tetapi juga mengarahkan alat pemotong (pahat) ketika proses produksi dilakukan.

Fixture adalah peralatan yang berfungsi untuk menahan benda kerja dan mendukung pekerjaan sehingga operasi pemesinan dapat dilakukan. Perancangan jig dan fixture disesuaikan dan dikhususkan untuk memegang dan menopang benda kerja tertentu karena jig dan fixture termasuk kedalam dedicated fixture atau dengan kata lain bahwa jig and fixture dirancang guna kebutuhan benda kerja tertentu.

\subsection{Prinsip Pencekaman (Workholding)}

Secara umum pencekaman (clamping) merupakan bagian peralatan produksi yang berfungsi menahan atau memegang benda kerja. Ditinjau dari clamping merupakan bagian dari jig dan fixture yang berfungsi mencekam benda kerja sehingga posisi benda kerja tidak berubah selama proses pemesinan. Tujuan utama dari proses pencekaman (clamping) adalah untuk menahan secara aman posisi benda kerja terhadap lokator selama siklus pemesinan. Ada beberapa prinsip jenis dan penempatan clamping, yaitu :

1. Gaya pencekaman adalah gaya yang dibutuhkan untuk menjaga posisi benda kerja selama proses pemesinan.

2. Besarnya gaya pencekaman tergantung dari besarnya gaya pemotongan dan cara peletakan benda kerja relatif terhadap pahat.

3. Gaya pencekaman hanya cukup untuk menahan benda kerja ke lokator. Gaya total harus ditahan oleh locator.

\subsection{Penentuan Besar Gaya Pencekaman}

Gaya pencekaman yang harus diberikan pada benda perlu ditentukan. Suatu pendekatan dalam menentukan besarnya gaya pencekaman yang harus diberikan pada benda kerja dapat ditentukan berdasarkan besarnya gaya permesinan terbesar yang akan terjadi selama pencekaman berlangsung. Perhitungan sederhana dapat dilakukan dengan menganggap gaya pemotongan oleh mesin bekerja seluruhnya pada arah horizontal dan benda kerja dapat ditahan secara stabil dengan memanfaatkan gaya gesek. Persamaan perhitungan gaya pencekaman tersebut dapat dilihat pada persamaan (1).

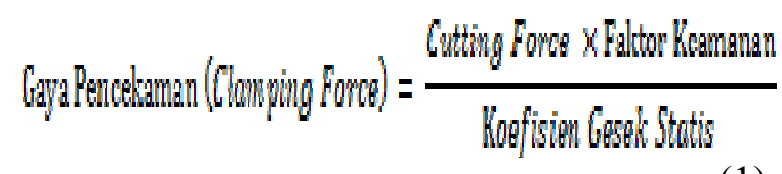

Prinsip Kesetimbangan Gaya Pada Benda Kerja yang Ditahan fixture. Hubungan antara gaya pencekaman, gaya reaksi pada lokator, dan gaya pemesinan dapat dinyatakan oleh persamaan (2).

$\sum_{i \in P} f_{i} \cdot w_{i}+\sum_{j \in A} f_{j} \cdot w_{j}+f_{k} \cdot w_{k}=0$

untuk semua $\mathrm{k}$ 
dimana:

$w_{i}=$ Arah gaya (colom wrench) yang bekerja pada locator ke-i.

$w_{j}=$ Arah gaya yang bekerja pada clamp ke-j.

$w_{k}=$ Arah gaya pemotongan $k$.

$f_{i}=$ Besarnya gaya (colom wrench) yang bekerja pada kolom ke-i.

$f_{j}=$ Besarnya gaya yang bekerja pada clamp ke-j.

$f_{k}=$ Besarnya gaya pemotongan $k$.

$P=$ Set seluruh lokator.

$A=$ Set seluruh clamp.

$K=$ Subscript gaya potong.

Persamaan (2) dapat ditulis dalam bentuk sebagai berikut:

$\left(W_{p} \cdot W_{a}\right)\left(F_{p} \cdot F_{a}\right)^{T}+f_{k} \cdot w_{k}=(0)$

atau

$W_{p} \cdot F_{p}+W_{a} F_{a}+f_{k} w_{k}=0$ untuk semua $k$

dimana:

$W_{p}=$ Matriks arah gaya yang bekerja pada lokator.

$W_{a}=$ Matriks arah gaya yang bekerja pada clamp.

$w_{k}=$ Matriks arah gaya pemotongan.

$F_{p}=$ Matriks gaya yang bekerja pada lokator.

$F_{a}=$ Matriks gaya yang bekerja pada clamp.

$f_{k}=$ Matriks gaya pemotongan.

$p=$ Pasif.

$a=$ Aktif.

Matriks $W_{p}, W_{a}$, dan $w_{k}$ disusun berdasarkan arah gaya dan momen dari suatu gaya tertentu dan terdiri dari tiga arah gaya pada sumbu $X, Y$, dan $Y\left(n_{x}, n_{y}, n_{z}\right)$ dan tiga momen terhadap sumbu $X, Y$, dan $Y\left(m_{x}, m_{y}\right.$, $\left.m_{z}\right)$. Dengan menghilangkan matriks $W_{p}$ pada baris sebelah kiri dari persamaan
(3) maka gaya reaksi di lokator $\left(F_{p}\right)$ dapat dihitung sebagai berikut :

$$
F_{p}=-W_{p}^{-1} \cdot W_{a} F_{a}-W_{p}^{-1} w_{k} f_{k}
$$

Persamaan (5) ini harus menghasilkan solusi non-negatif untuk $F_{p}$, yang artinya setiap lokator memiliki kontak dengan benda kerja. Penyusunan invers dari matriks $W_{p}$ dapat dinyatakan sebagai berikut :

$W_{p}=\left(\begin{array}{ll}A & O \\ T & B\end{array}\right)$

dan

$W_{p}^{-1}=\left(\begin{array}{cc}A^{-1} & O \\ -B^{-1} T \cdot A^{-1} & B^{-1}\end{array}\right)$.

Pada tahap penempatan (locating stage), benda kerja didorong oleh gaya luar, yaitu gaya penempatan $f_{t}$, pada arah yang berlawanan dengan arah gaya lokator $\left(w_{l}\right)$. Pada tahap ini benda kerja belum dicekam sehingga belum ada gaya pencekaman. Persamaan (5) dapat dituliskan menjadi :

$W_{p} F_{p}=-w_{l} f_{l} \quad$ atau $\quad F_{p}=-W_{p}^{-1} w_{l} f_{l}$

dimana :

$w_{l}=$ Arah gaya penempatan

$f_{l}=$ Besar gaya penempatan

Persamaan (8) harus menghasilkan solusi non-negatif untuk $F_{p}$, yang artinya setiap lokator memiliki kontak dengan benda kerja. Pada tahap pencekaman (clamping stage), gaya luar $\left(f_{l}\right)$ sudah tidak bekerja lagi sedangkan gaya pemesinan belum bekerja, sehingga persamaan yang berlaku adalah :

$F_{p}=-W_{p}^{-1} \cdot W_{a} F_{a}$ 
Persamaan (9) harus menghasilkan solusi non-negatif untuk $F_{p}$, yang artinya setiap lokator memiliki kontak dengan benda kerja.

Pada tahap pemesinan, gaya potong dan gaya pencekaman bekerja pada benda kerja, sehingga persamaan yang berlaku adalah :

$F p=-W_{p}^{-1} W_{k} F_{k}+\left(-W_{p}^{-1} W_{a} F_{a}\right)$

Persamaan (10) harus menghasilkan solusi non-negatif untuk $F_{p}$, yang artinya setiap lokator memiliki kontak dengan benda kerja.

\section{HASIL DAN PEMBAHASAN}

Perancangan jig dan fixture dilakukan untuk mempermudah proses pelubangan di tiga permukaan yang pada kondisinya saat ini menggunakan tiga alat bantu. Produk yang menjadi objek penelitian perancangan jig dan fixture adalah produk cover on-off yang menjadi salah satu komponen pengereman kereta api. Gambar 1 dan gambar 2 merupakan gambar produk cover on-off yang digunakan sebagai acuan dalam pembuatan rancangan jig dan fixture.

Proses pelubangan pada produk cover on-off untuk saat ini sudah dibantu dengan penggunaan alat bantu jig dan fixture. Alat bantu jig dan fixture yang digunakan saat ini terdiri dari tiga buah, yang masing - masing alat bantu tersebut digunakan untuk memproses permukaan benda kerja yang berbeda sehingga waktu setup yang dihasilkan menjadi lebih lama karena membutuhkan proses loading dan unloading pada masing-masing penggunaan alat bantu jig dan fixture tersebut.
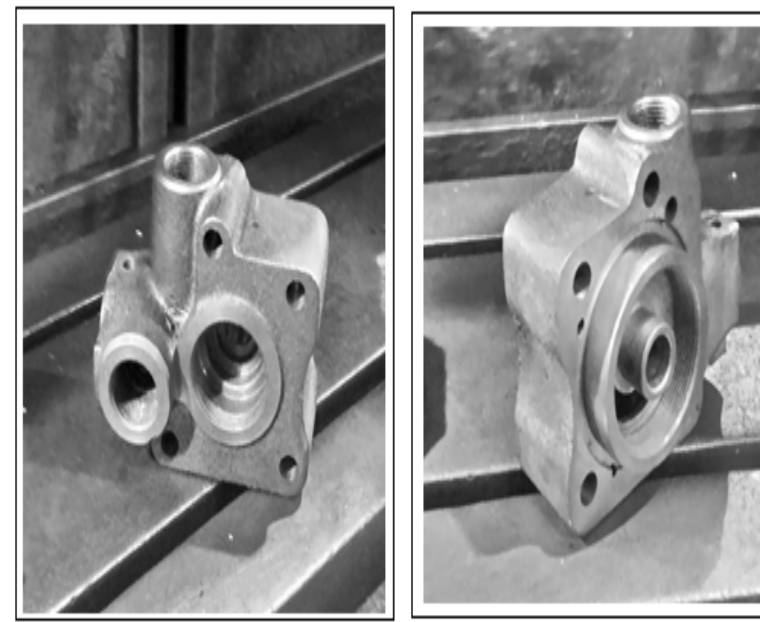

Gambar 1. Produk Cover On-Off.

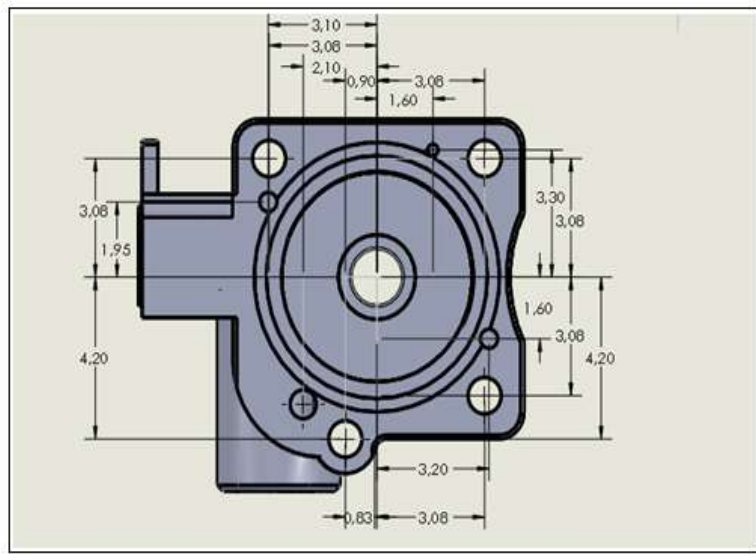

Gambar 2. Gambar Teknik Produk

Cover On-Off.

Perancangan jig dan fixture untuk proses pelubangan cover on-off dilakukan untuk memperbaiki alat bantu yang telah ada. Salah satunya yaitu untuk dapat membantu operator dalam melakukan proses pelubangan. Selain itu, perancangan jig dan fixture ini dapat mempercepat waktu setup yang dilakukan oleh operator karena penggunaan alat bantu yang lebih sedikit dan mudah di operasikan. 


\subsection{Perancangan Jig dan Fixture}

Dalam perancangan jig dan fixture yang dilakukan ini hanya mencakup tiga buah proses pelubangan dari empat proses pelubangan yang dilakukan pada produk cover on-off. Hal tersebut dilakukan karena ketiga proses pelubangan ini memiliki sumbu putar yang sama sehingga dapat di lakukan proses dalam satu alat bantu seperti rancangan yang dilakukan, kecuali proses pelubangan dengan kemiringan $45^{\circ}$ (derajat). Terdapat beberapa tahap dalam melakukan perancangan, salah satunya dengan melakukan pemilihan dan merancang komponen yang dibutuhkan dalam perancangan jig and fixture seperti baseplate atau landasan, lokator, dan toogle-action clamp.

\subsection{Perancangan Base Plate}

Perancangan dudukan baseplate dilakukan sebagai penopang utama dari fixture sehingga fixture yang dirancang memungkinkan untuk dapat diputar $360^{\circ}$ (derajat). Dudukan baseplate dirancang dengan berbentuk $U$ yang pada kedua dinding sisinya tersebut memiliki lubang yang berfungsi sebagai tempat masuknya poros dengan bantalan bearing. Pada salah satu dinding sisinya tersebut memiliki 2 buah lubang yang berfungsi sebagai tempat masuk pin pengunci agar pada saat di proses, fixture tersebut tidak bergerak. Gambar rancangan baseplate beserta dimensinya masing - masing dan bagian yang terdapat pada baseplate dapat dilihat pada gambar 3 dan gambar 4.

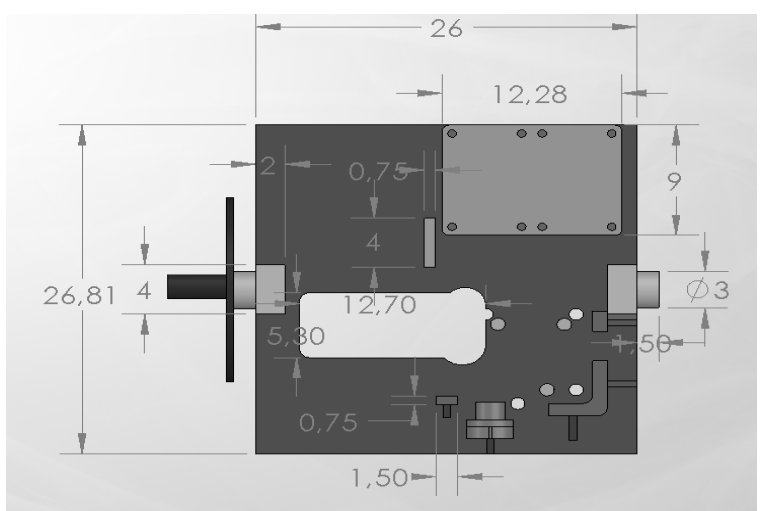

Gambar 3. Perancangan Baseplate

Tampak Atas.

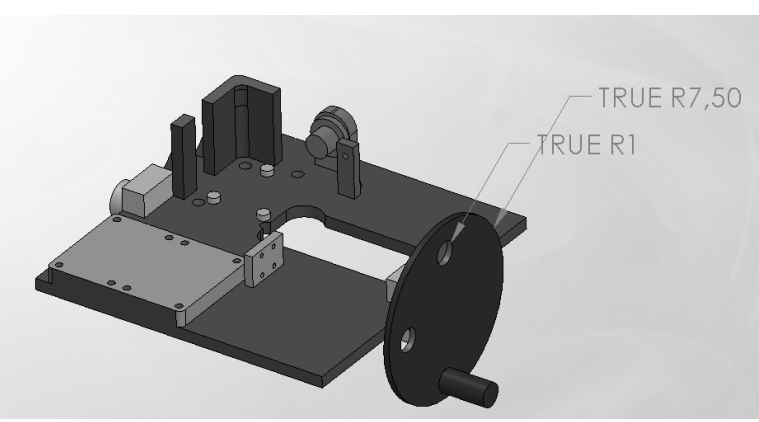

Gambar 4. Perancangan Baseplate Isometri.

\subsection{Perancangan Lokator}

Lokator yang berfungsi untuk menahan beban benda kerja dan menjamin penopangan yang kaku disebut support (penopang) sedangkan lokator yang berfungsi untuk menghasilkan titik / bidang referensi pada sisi benda disebut stopper. Fixture yang dirancang menggunakan prinsip 3-2-1 untuk penempatan lokatornya., dimana pada rancangan yang dibuat menggunakan 3 buah lokator yang berfungsi sebagai penopangan benda kerja pada saat proses permesinan nantinya, 3 buah clamping yang berfungsi sebagai pencekaman yang ditambahkan dengan komponen tambahan sehingga nantinya 2 buah clamping tersebut menjadi satu kesatuan, serta satu buah stopper yang berfungsi sebagai titik acuan saat penempatan benda kerja pada rancangan fixture. Rancangan lokator dapat dilihat pada gambar 5 dan 6.

Support yang terdiri dari 3 buah ini dirancang dengan bentuk tabung dimana 2 dari 3 support mengikuti titik center lingkaran yang akan di proses pada benda kerja dan di posisikan sedemikian rupa sehingga tidak mengganggu pergerakan pahat. Kemudian 1 dari 3 buah komponen support diposisikan pada tengah-tengah dua buah silinder yang akan di proses. Ketiga support tersebut memiliki ukuran diameter $10 \mathrm{~mm}$ dan tinggi $7 \mathrm{~mm}$.

Clamping yang digunakan untuk mencekam benda kerja adalah jenis togle action clamp, karena dilihat dari pengoprasian clamping jenis ini yang cukup sederhana. Selain pengoprasiannya yang sederhana, pemilihan tersebut dilakukan sebagai salah satu langkah untuk 
meminimasi waktu setup pada penggunaan rancangan ini. Pada salah satu bagian clamping pada rancangan ini di tambahkan menggunakan komponen custom yang nantinya akan dimemiliki bentuk persegi panjang yang mengikuti bentuk alur dari benda kerja sehingga pada saat dilakukan pencekaman dapat mencekam benda kerja dengan baik.

Lokator lain yaitu stopper yang terdiri dari satu buah ini dirancang mengikuti bentuk tabung yang terdapat pada benda kerja bagian atas, namun ukuran silinder pada stopper ini dirancang lebih kecil karena difungsikan agar stopper ini dapat masuk kedalam silinder yang ada pada benda kerja. Ketiga jenis lokator tersebut menggunakan bahan yang sama seperti halnya bahan baseplate yaitu ST-40 karena murah dari segi harga dan mudah di dapat.

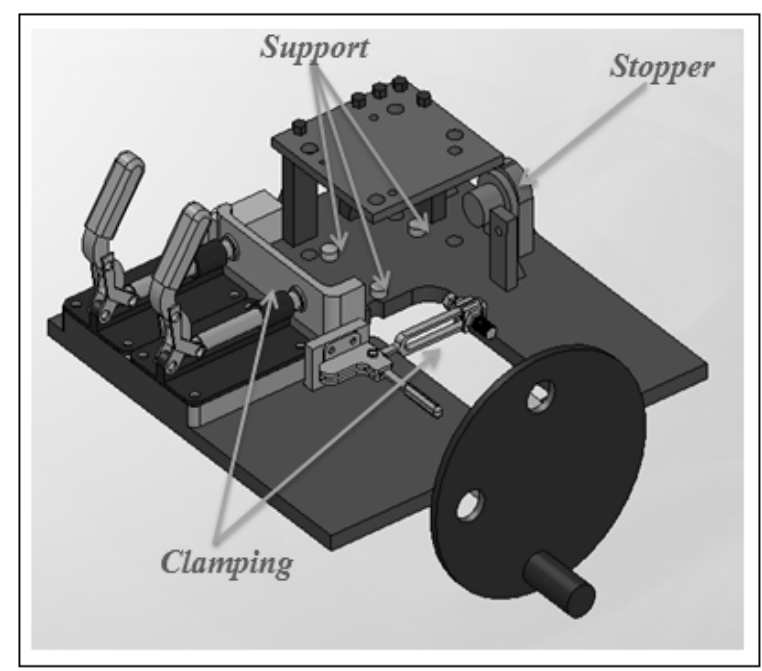

Gambar 5. Perancangan Support, Stopper, Clamping.

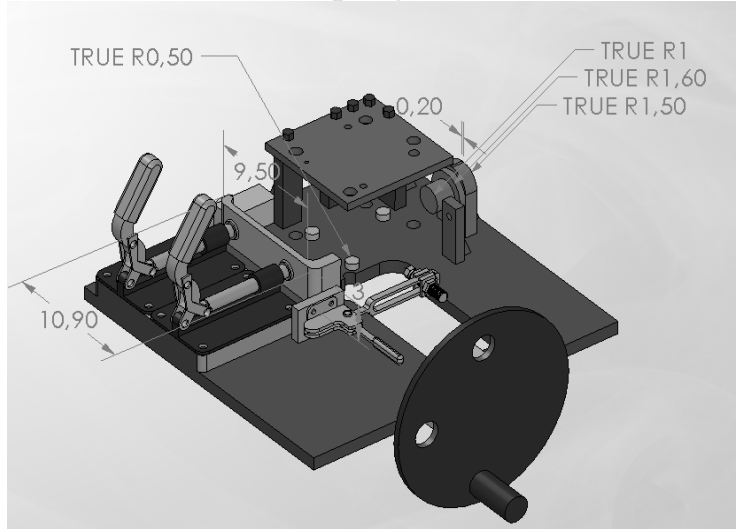

Gambar 6. Posisi Penempatan Support, Stopper, Clamping.
Clamping diposisikan berdasarkan daerah pencekaman pada daerah benda kerja yang tidak mengalami proses permesinan, sehingga clamping yang di pasang tidak mengganggu pergerakan pahat, kerja operator dan mampu mencekam benda kerja dengan maksimal. Gaya pencekaman yang di berikan terdiri dari 2 (dua) arah, yaitu pencekaman yang searah dengan sumbu Y, dan pencekaman yang mengarah pada sumbu $\mathrm{X}$. dilihat dari besar gaya yang ditimbulkan oleh pencekaman, arah pencekaman yang saling tegak lurus dengan sumbu $Y$ menimbulkan gaya pencekaman yang paling besar, karena clamping ini terdiri dari 2 (dua) toggle action clamp yang dirakit bersamaan pada sebuah komponen lain untuk pencekaman, sehingga memungkinkan untuk digerakan bersamaan. Gaya pencekaman ini mengarah pada set-block dan stopper yang menahan arah gaya dan menjaga kestabilan untuk benda kerja dari gaya yang diberikan oleh clamping.

Gaya pencekaman lain yang ditimbulkan adalah clamping yang memberikan arah gaya pencekaman searah dengan sumbu $\mathrm{X}$, gaya yang di berikan oleh clamping ini tidak sebesar gaya yang searah dengan sumbu Y, karena gaya pencekaman yang ditimbulkan hanya terdiri dari 1 (satu) toggle action clamp. Gaya tersebut mengarah pada set-block yang menahan arah gaya dan menjaga kestabilan untuk benda kerja dari gaya yang diberikan oleh clamping. Persamaan perhitungan gaya pencekaman tersebut dapat dilihat pada persamaan (2).

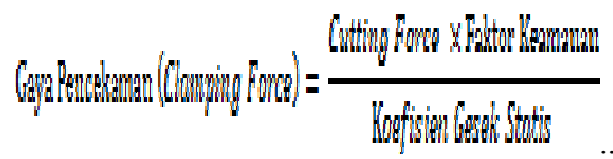

Gaya Pencekaman $=$ $61565,6576 \times 23,2571 \mathrm{~cm} / \mathrm{min} \times 9,6 \mathrm{~mm}$ $5966,499 \mathrm{rpm}=2304,03$ Newton.

Berdasarkan perhitungan besar gaya yang akan diterima oleh benda kerja pada saat permesinan, membuat pemakaian clamp 
harus memberikan gaya yang lebih besar dibandingkan gaya yang akan timbul. Pada dasarnya setiap jenis toggle action clamp memiliki besar kekuatan gaya maksimum yang dapat di timbulkan, sehingga pemilihan clamp disesuaikan dengan besar gaya yang diinginkan. Jenis toggle action clamp yang akan dipilih adalah jenis toggle yang memiliki kekuatan cekam maksimum sebesar $2450 \mathrm{~N}$. Jenis tersebut dipilih untuk pencekaman yang nantinya akan dirakit dengan menggunakan komponen tambahan, yang dirancang menggunakan 2 (dua) buah toggle sehingga total gaya yang akan di berikan adalah sebesar $4900 \mathrm{~N}$.

\subsection{Perancangan Poros}

Rancangan diameter poros ini berdasar pada baseplate yang dirancang tersebut dapat berputar $360^{\circ}$. Pada dasarnya perhitungan poros ini terdapat 2 (dua) kondisi dimana rumus yang digunakan untuk perhitunganpun berdasarkan kondisi yang terjadi pada rancangan yang di buat. Kondisi yang pertama, poros yang memiliki beban sebesar $15 \mathrm{~kg}$ (beban fixture dan benda kerja), akan mendapatkan gaya sebesar $\mathrm{N}$ ketika poros dalam keadaan berputar. sehingga dapat digunakan persamaan (2.18) dan persamaan (2.19). Kondisi kedua, poros memiliki beban sebesar $15 \mathrm{~kg}$, akan mendapatkan gaya sebesar $\mathrm{N}$ ketika poros dalam keadaan diam. Poros menerima gaya sebesar $\mathrm{N}$ ketika poros tersebut berada dalam keadaan diam, karena pada saat dilakukan pemrosesan, baseplate tersebut akan dikunci sehingga pergerakan rotasi pada fixture dapat diredam. Besar diameter poros yang di sarankan untuk estimasi beban sebesar $15 \mathrm{~kg}$ dapat diselesaikan dengan persamaan (12).

$d_{s} \quad=\left[\frac{10,2}{\sigma_{a}} M_{11}\right]^{1 / 3}$

Dimana :

$$
\begin{aligned}
\sigma_{a} & =\frac{40 \mathrm{~kg} / \mathrm{mm}^{2}}{6 \times 4} \\
& =1,667 \mathrm{~kg} / \mathrm{mm}^{2}
\end{aligned}
$$

Besar momen yang terdapat didalam perhitungan ini ialah berdasarkan momen terbesar yang terjadi pada rancangan.

$\mathrm{M} \quad=$ Beban $(\mathrm{kg}) \times$ Jarak $(\mathrm{mm})$

$=15 \mathrm{~kg} \times 220 \mathrm{~mm}$

$=3.300 \mathrm{~kg} \mathrm{~mm}$

$$
\begin{aligned}
d_{s} & =\left[\frac{10,2}{1,667} \times 3300\right]^{1 / 3} \\
& =27,2325 \mathrm{~mm} .
\end{aligned}
$$

Diameter poros yang direkomendasikan dengan bahan baku ST-40 agar dapat menopang beban seberat $15 \mathrm{~kg}$ adalah minimal $2,8 \mathrm{~cm}$.

\subsection{Matriks Gaya Penempatan, Pencekaman dan Permesinan}

Perhitungan matriks ini dilakukan untuk mengetahui apakah rancangan yang dilakukan sudah baik atau belum, dilihat dari perhitungan matriks penempatan, pencekaman dan permesinan tidak bernilai negatif. Perhitungan yang dilakukan melibatkan titik locator (support, set-block, dan stopper), yaitu titik yang saling memotong ataupun saling berlawanan dengan arah gaya berat dari benda kerja, maupun yang berlawanan dengan arah pencekaman, titik pencekaman (clamping), yaitu gaya pencekaman, serta titik permesinan yaitu gaya permesinan. Gambar penempatan lokator dapat dilihat pada gambar 5. Gambar titik koordinat peletakan benda kerja dari tampak atas dapat dilihat pada gambar 7. Calon titik lokator (setblock, Support, dan stopper) yang bersentuhan langsung dengan benda kerja sesuai dengan koordinat pada rancangan dapat dilihat pada tabel 1 .

Matriks penempatan ini, setiap lokator akan diuji dengan menggunakan perhitungan matriks tanpa melibatkan gaya pencekaman ataupun permesinan. Setelah memodifikasi titik locator, langkah selanjutnya adalah melakukan perhitungan matriks. Apabila hasil perhitungan menghasilkan nilai negatif, maka peletakan locator pada rancangan yang dibuat tersebut harus di modifikasi kembali 
sampai dengan hasil perhitungan matriks tidak bernilai negatif. Berikut ini merupakan perhitungan matriks penempatan dengan nilai $W p, W l, F l$,dan $F p$ :

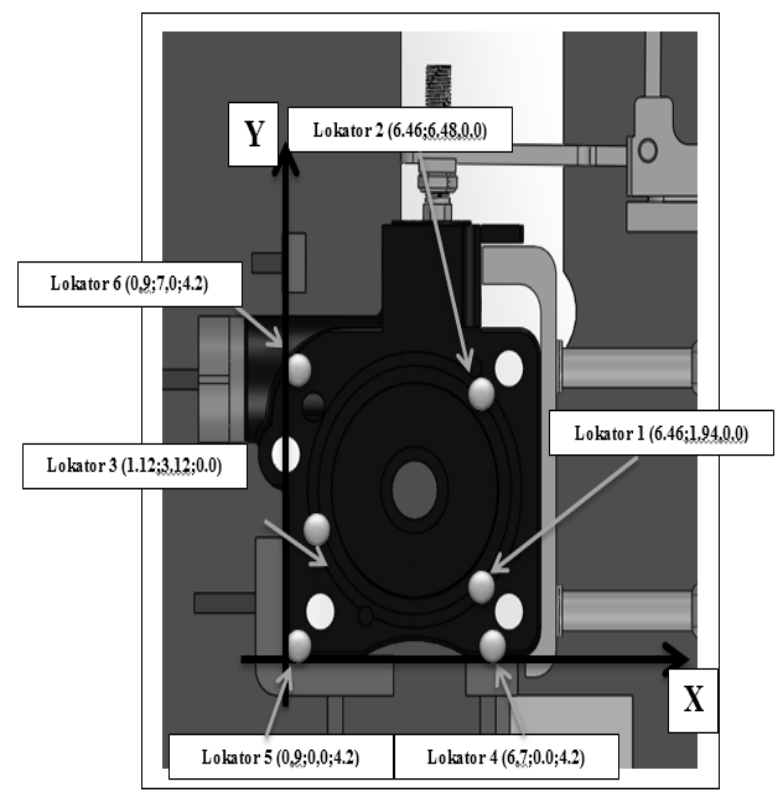

Gambar 7. Gambar Titik Koordinat Peletakan Benda Kerja.

Tabel 1. Calon Titik Lokator Pada Rancangan

\begin{tabular}{cccc}
\hline Locator & $\mathbf{X}$ & $\mathbf{Y}$ & $\mathbf{Z}$ \\
\hline 1 & 6,46 & 1,94 & 0 \\
2 & 6,46 & 6,48 & 0 \\
3 & 1,12 & 3,12 & 0 \\
4 & 6,7 & 0 & 4,2 \\
5 & 0,9 & 0 & 4,2 \\
6 & 0,9 & 7 & 4,2 \\
\hline
\end{tabular}

$F p$ bernilai non-negatif, hal tersebut menandakan bahwa terjadi kontak antara benda kerja dan lokator pada saat benda kerja di tempatkan. Benda kerja dalam keadaan seimbang atau gaya yang diterima oleh lokator dapat menahan gaya berat dari benda kerja.

Pada tahap pencekaman ini setiap lokator diuji apakah terjadi kontak dan bekerja dengan benda kerja selama tahap pencekaman ini. Setiap titik lokator diuji menggunakan perhitungan matriks. Untuk menentukan besarnya gaya yang berlangsung selama pencekaman maka dilakukan perhitungan gaya pencekaman. Besar gaya pencekaman yang diperoleh adalah 2304,033 Newton. Berikut ini merupakan perhitungan matriks pencekaman dengan nilai $W a, F a$, dan $F p$ :

$$
\begin{array}{r|c|c|c|} 
& & \text { W1 } & \text { W2 } \\
\mathrm{Wa} & 0 & 0 \\
\mathrm{ny} & -1 & 0 \\
\mathrm{mz} & 7 & 0 \\
\mathrm{nz} & 0 & -1 \\
\mathrm{mx} & -9,45 & -7 \\
\mathrm{ma} & 0 & 5
\end{array}
$$

Fp bernilai non-negatif, hal tersebut menandakan bahwa terjadi kontak antara benda kerja selama bekerjanya gaya pencekaman. Pada tahap permesinan ini setiap locator diuji apakah terjadi kontak dan bekerja dengan benda kerja selama tahap permesinan ini. Berikut ini merupakan perhitungan matriks gaya pemesinan :

$\mathrm{Wk}=$\begin{tabular}{c|c|c|c|}
$\mathrm{nx}$ & 0 & $\mathrm{~W} 1$ & $-118,20$ \\
$\mathrm{ny}$ & 0 & $\mathrm{ny}$ & 389,22 \\
$\mathrm{mz}$ & 0 & $\mathrm{mz}$ & 101,98 \\
$\mathrm{nz}$ & -1 & $\mathrm{nz}$ & 0,00 \\
$\mathrm{mx}$ & -7 & $\mathrm{mx}$ & 0,00 \\
$\mathrm{my}$ & 5 & $\mathrm{my}$ & 0,00
\end{tabular}




$$
\mathrm{fk}=\mathrm{Fp}=\begin{array}{c|c|}
\mathrm{nx} & 3655,46 \\
\mathrm{ny} & 603,30 \\
\mathrm{mz} & 3027,70 \\
\mathrm{nz} & 0,00 \\
\mathrm{mx} & 0,00 \\
\mathrm{my} & 6912,10
\end{array}
$$

$F p$ bernilai non-negatif, hal tersebut menandakan bahwa terjadi kontak antara benda kerja dan lokator selama bekerjanya gaya permesinan.

Dari hasil pengujian menunjukkan secara matematik bahwa rancangan jig dan fixture dapat memberikan posisi benda kerja yang rigid selama proses pemesinan, sehingga usulan jig dan fixture dapat digunakan. Berikut merupakan rancangan pada saat jig and fixture dalam keadaan utuh dan dalam keadaan tanpa benda kerja pada tampak isometri dapat dilihat pada gambar 8 dan gambar 9.

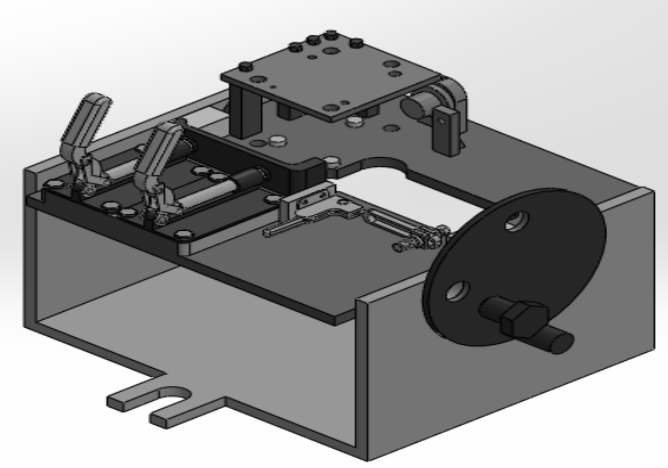

Gambar 8. Rancangan Utuh Jig and Fixture Tampak Isometri Tanpa Benda Kerja.

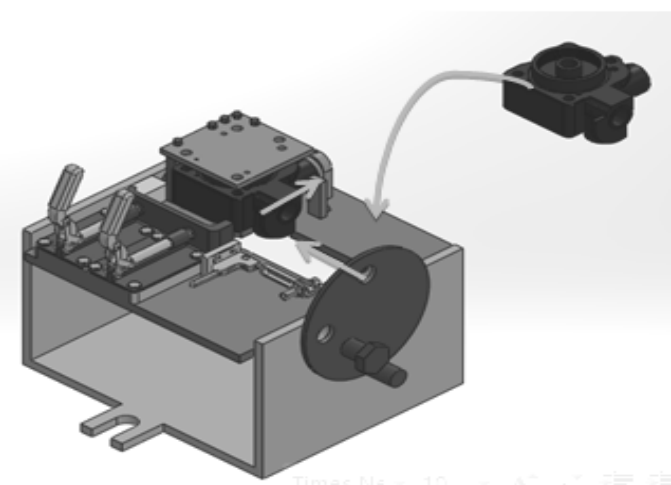

Gambar 9. Rancangan Utuh Tampak Isometri dan Benda Kerja Dengan Clamp Terbuka.
Hasil rancangan utuh dan benda kerja, dengan kondisi clamping tertutup dapat dilihat pada gambar 10 .

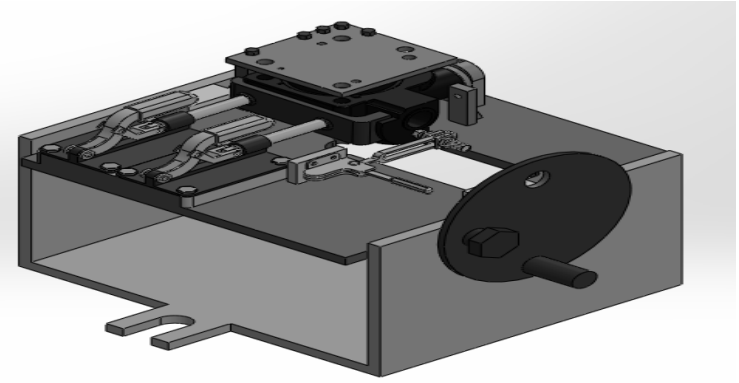

Gambar 10 Rancangan Utuh Tampak Isometri dan Benda Kerja Dengan Clamping Tertutup.

\subsection{Analisis Waktu Penggunaan Jig and Fixture}

Rancangan jig dan fixture yang dilakukan mampu menghasilkan waktu setup yang lebih kecil dibandingkan dengan waktu setup alat bantu sebelumnya yang secara tidak langsung akan berdampak pada waktu pengerjaan suatu komponen menjadi lebih cepat. Perhitungan waktu menggunakan metode motion time measurement baik pada setup sebelum menggunakan alat bantu jig dan fixture saat ini maupun waktu setup menggunakan usulan rancangan jig dan fixture yang dilakukan. Perbandingan waktu untuk kedua alat bantu tersebut dapat dilihat pada tabel 2 dan tabel 3.

Tabel 2 Waktu Penggunaan Alat Bantu Sekarang

\begin{tabular}{l|cc} 
& $\begin{array}{l}\text { Waktu } \\
\text { (Menit) }\end{array}$ & $\begin{array}{l}\text { Jumlah } \\
\text { Benda } \\
\text { Kerja } \\
\text { (Unit) }\end{array}$ \\
Waktu Setup Loading & 2,55 & \\
\& Unloading & 3,00 & 1 \\
Waktu Permesinan & 1 \\
Total Waktu Setup & 5,55 & \\
\hline
\end{tabular}


Tabel 3 Waktu Penggunaan Usulan Rancangan Jig and Fixture

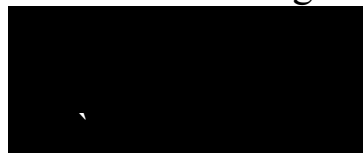
Waktu Jumlah Waktu Benda (Menit)

\begin{tabular}{lrrr} 
Waktu $\quad$ Setup & & \\
Loading $\quad \&$ & 0,76 & 1 \\
Unloading & & & \\
Waktu Permesinan & 3,00 & \\
Total Waktu Setup & 3,76 & \\
\hline
\end{tabular}

Waktu yang dihasilkan oleh penggunaan usulan rancangan jig dan fixture lebih kecil dibandingkan waktu penggunaan alat bantu yang saat ini digunakan. Hal tersebut dapat dikarenakan pada alat bantu sebelumnya terdiri dari tiga buah alat bantu yang pastinya membutuhkan waktu lebih lama pada saat kegiatan setup alat bantu dilakukan, sedangkan pada alat bantu yang dirancang hanya terdiri dari satu buah alat bantu yang dapat melakukan tiga proses dengan permukaan benda kerja yang berbeda.

\subsection{Analisis Produktivitas penggunaan Jig dan fixture}

Perbandingan produktivitas yang dihasilkan berdasarkan penggunaan jig and fixture sebelum dan penggunaan jig dan fixture usulan dapat dilihat pada tabel 4.

Tabel 4 Perbandingan Produktivitas

Penggunaan Alat Bantu Sekarang dan Usulan

\begin{tabular}{lccl} 
& $\begin{array}{l}\text { Jumlah } \\
\text { Produk / } \\
\text { Jam } \\
\text { (Unit) }\end{array}$ & $\begin{array}{l}\text { Jumlah } \\
\text { Produk / } \\
\text { Hari } \\
\text { (Unit) }\end{array}$ & $\begin{array}{l}\text { Jumlah } \\
\text { Produk } \\
\text { (Unit) }\end{array}$ \\
\hline $\begin{array}{l}\text { Alat Bantu } \\
\text { Sekarang } \\
\text { Alat Bantu } \\
\text { Usulan }\end{array}$ & 10,80 & 86,46 & 1729,10 \\
\hline
\end{tabular}

Penggunaan usulan rancangan jig and fixture menghasilkan nilai produktivitas yang lebih besar karena total waktu proses benda kerja cover on-off menjadi lebih cepat yang berbeda dengan alat bantu yang saat ini digunakan. Pada usulan rancangan pun tidak perlu operasi tambahan yang mengharuskan operator melakukan pengaturan atau pemposisian benda kerja terhadap jig maupun fixture seperti pada alat bantu sebelumnya.

\subsection{Analisis Kelayakan Ekonomis Alat Bantu Produksi}

Analisis kelayakan ekonomis dilakukan untuk melihat apakah Jig dan fixture yang dibuat cukup layak secara ekonomis. Hasil analisis kelayakan ekonomis dapat perbandingan dapat dilihat pada tabel 5 .

Tabel 5 Perbandingan Ongkos antara Jig dan Fixture yang Lama dan yang Baru

\begin{tabular}{lcc}
\hline \multicolumn{1}{c}{ Kriteria } & $\begin{array}{c}\text { Jig dan } \\
\text { fixture yang } \\
\text { lama }\end{array}$ & $\begin{array}{c}\text { Jig dan } \\
\text { fixture } \\
\text { Usulan }\end{array}$ \\
\hline $\begin{array}{l}\text { Ukuran Lot } \\
\text { Produksi }\end{array}$ & 12.000 unit & 12.000 unit \\
$\begin{array}{l}\text { Jumlah Benda } \\
\text { kerja per Jam }\end{array}$ & 10,80 unit/ jam & 15,95 unit/ jam \\
$\begin{array}{l}\text { Ongkos Tenaga } \\
\text { Kerja } \\
\text { Ongkos } 15.268 .055\end{array}$ & Rp. 10.344.922 \\
pembuatan/unit & Rp. 1.788,74 & Rp. 1.267,42 \\
\hline
\end{tabular}

Hasil perbandingan menunjukkan bahwa penggunaan jig dan fixture usulan dapat meningkatkan volume produksi yang berakibat pada penurunan biaya pembuatan produk. 


\section{KESIMPULAN}

Rancangan Jig dan Fixture yang dibuat dapat digunakan sebagai alat bantu produksi pembuatan produk cover on-off. Rancangan Jig dan Fixture dapat memberikan penurunan total waktu pembuatan produk, peningkatan kualitas produk, peningkatan produktivitas dan penghematan biaya.

\section{DAFTAR PUSTAKA}

Chou et al, A Mathematical Aproach To Automatic Conviguration of Machining Fixture : Analysis and Syinthesis, Transaction of The ASME, Journal of Engineering For Industry, 1989.

Hoffman, Edward G, JIG AND FIXTURE DESIGN Fourth Edition, Delmar Publisher, 1996.

Rizki, Ahmad, Perancangan Fixture Berbantuan Komputer Untuk Benda Kerja Prismatik Pada Mesin Milling Vertikal, Tugas Akhir Sarjana, Departemen Teknik Industri, Institut Teknologi Bandung, 2003.

Sularso, Kiyokatsu Suga, Dasar Perencanaan Dan Pemilihan Elemen Mesin, Cetakan ke dua belas, PT.Pradnya Paramita, Jakarta, 2008. 